\title{
Comparison of satellite altimetry sea level anomalies and hydrographic observations in the Mediterranean Sea
}

\author{
FRANCISCO MIR CALAFAT and MARTA MARCOS MORENO
}

IMEDEA (CSIC-UIB), Miquel Marquès, 21, 07190 Esporles, Mallorca, Spain. E-mail: Francisco.Calafat@noc.ac.uk

SUMMARY: Steric sea level (SSL) computed from hydrographic observations in the Mediterranean Sea is compared against altimetric sea level anomalies (SLA) at seasonal and inter-annual time scales for the period 1993-2008. SSL (referenced to $300 \mathrm{~m}$ ) is computed using two data sets: in situ profiles and gridded products obtained from interpolated observations. The impact of expendable/mechanical bathythermograph (XBT/MBT) biases affecting some of the in situ profiles is investigated by comparing both corrected and uncorrected data. For the period 2003-2008 the mass component is estimated from GRACE observations and subtracted from SLA. The analysis of the spatio-temporal distribution of profiles shows that the number of profiles with data below $300 \mathrm{~m}$ is a small percentage of the total and that their spatial coverage of the Mediterranean basin is very limited. This is an important handicap for regions where the contribution of the deep layers to SSL is significant. Overall, SSL and SLA are shown to be consistent in the Mediterranean at seasonal time scales, although the annual amplitude of the SSL from in situ profiles and interpolated data is considerably smaller than that of the SLA. The agreement at interannual time scales is less good. At some particular locations SSL computed from individual profiles is more correlated with SLA than the gridded products. At basin and sub-basin scales, however, interpolated and in situ observations provide similar results in terms of their correlation with observed SLA. The XBT/MBT bias corrections have little effect on the SSL at the time scales considered in this study.

Keywords: steric sea level, hydrographic observations, Mediterranean Sea, satellite altimetry, in situ profiles, gridded products.

RESUMEN: COMPARACIÓN DE ANOMALÍAS DE NIVEL DEL MAR ALTIMÉTRICAS CON OBSERVACIONES HIDROGRÁFICAS EN EL MAR MEDITERRÁNEO. - En este artículo comparamos la componente estérica del nivel del mar calculada a partir de observaciones hidrográficas en el mar Mediterráneo con anomalías de nivel del mar altimétricas a escala de tiempo estacional e inter-anual para el periodo 1993-2008. La componente estérica (referenciada a una profundidad de $300 \mathrm{~m}$ ) se calcula a partir de dos conjuntos de datos: perfiles in situ y datos en malla obtenidos a partir de la interpolación de observaciones. El impacto de los sesgos en los XBT/MBT que afectan algunos perfiles in situ se ha investigado comparando dos conjuntos de datos de perfiles, uno corregido y otro sin corregir. Para el periodo 2003-2008 sustraemos de las anomalías de nivel del mar una estima de la componente de masa obtenida a partir de datos GRACE. El análisis de la distribución espacio-temporal de los perfiles muestra que el número de perfiles con observaciones por debajo de $300 \mathrm{~m}$ supone un porcentaje pequeño del total y que su cobertura espacial del Mediterráneo es muy limitada. Esta es una limitación importante para las regiones en las que la contribución de las capas más profundas al nivel estérico es significativa. En general, la componente estérica y las anomalías de nivel del mar muestran un comportamiento coherente a escala de tiempo estacional, aunque la amplitud anual del nivel estérico es considerablemente más pequeña que la de las anomalías del nivel del mar. A escala inter-anual el comportamiento es menos bueno. En algunas zonas particulares el nivel estérico calculado a partir de datos in situ muestra una correlación más alta con las anomalías de nivel del mar que el calculado a partir de datos interpolados. Sin embargo, a escalas de cuenca y sub-cuenca los datos interpolados y los in situ dan resultados similares en términos de su correlación con las anomalías de nivel del mar. Las correcciones de los sesgos en los XBT/MBT aplicadas a los perfiles tienen un impacto pequeño sobre el nivel estérico en las escalas temporales consideradas en este estudio.

Palabras clave: nivel estérico del mar, observaciones hidrográficas, mar Mediterráneo, altimetría, perfiles in situ, productos interpolados. 


\section{INTRODUCTION}

Once the response to the atmospheric forcing has been removed, long-term sea level variability is controlled by two main driving mechanisms: changes in the water content of the oceans and changes in the density of the water column. The latter, referred to as 'steric sea level' (SSL), is due to temperature (T) and salinity (S) changes and is the main cause of spatial sea level variability (Lombard et al. 2005, Willis et al. 2010, Cazenave and Llovel 2010).

SSL can be estimated from in situ hydrographic observations provided by instruments and sensors such as conductivity-temperature depth (CTD) profilers, expendable and mechanical bathythermographs (XBTs and MBTs) and Argo profilers. Major shortcomings of hydrographic measurements are the scarcity of historical observations during the last few decades, their uneven distribution in space and time and the poor coverage of the deep ocean below $700 \mathrm{~m}$. In addition, several problems have been reported with some of the observations, especially with XBT data, which account for the majority of observations before the 1980s. XBT data were found to have systematic biases in $\mathrm{T}$ due to errors in the depth of the observations. The correction of these warming biases has resulted in a lower decadal variability of the ocean heat content (Gouretski and Koltermann 2007, Wijffels et al. 2008, Willis et al. 2009). Updated estimates of global warming trends are $0.36 \pm 0.06 \mathrm{~W} / \mathrm{m}^{2}$ for the period 1961-2003 (Domingues et al. 2008) and $0.64 \mathrm{~W} / \mathrm{m}^{2}$ for the period 1993-2008 (Lyman et al. 2010). The problems affecting hydrographic observations have been partially overcome with the development of the Argo buoys and their massive deployment during the first decade of the $21^{\text {st }}$ century. Argo observations provide a global coverage down to $2000 \mathrm{~m}$ (http://www.argo.net/), with more than $90 \%$ of oceanic areas sampled since 2006 (Cazenave et al. 2009).

In situ measurements can be combined through spatio-temporal interpolations to obtain global 3D fields of the thermohaline properties of the ocean (Ingleby and Huddleston 2007, Levitus et al. 2009, Ishii and Kimoto 2009). In fact, most of the available SSL estimates have been obtained from gridded hydrographic products spanning the last few decades (e.g. Lombard et al. 2005, Antonov et al. 2005, Chambers 2006a, Fenoglio-Marc et al. 2006, Calafat et al. 2010, Marcos et al. 2011). Assessing the reliability of these SSL estimates is essential, given the limitations of the historical data sampling reported above. This question must necessarily be addressed regionally due to the heterogeneous distribution of the observations.

In this paper we compare altimetry sea level anomalies (SLA) covering the whole Mediterranean Sea with SSL obtained both from interpolated T and S fields and from individual profiles. In order to explore the impact of the XBT/MBT bias corrections, the SSL is computed using both corrected and uncorrected in situ profiles. At global scale SLA and SSL are highly correlated at both intra and inter-annual time scales (Guinehut et al. 2006, Dhomps et al. 2011). In the Mediterranean Sea, however, they are highly correlated only at intra-annual scales, since at scales longer than the seasonal cycle sea level is dominated by the mass component (Calafat et al. 2010). Hence, at interannual time scales, an estimate of the regional mass component needs to be removed from SLA before they are compared with the SSL. This estimate was obtained from GRACE observations for the period 2003-2008. At inter-annual scales the comparison between masscorrected SLA and SSL is restricted to basin-average estimates because of the poor horizontal resolution of GRACE observations. Summarizing, we use the relationship between SLA and SSL to explore the representativeness of gridded data at basin and sub-basin scales in the Mediterranean Sea with respect to noninterpolated observations. The spatio-temporal distribution of hydrographic measurements (including their vertical coverage) is also investigated, and a choice of the reference level to be used for the computation of SSL is proposed.

The paper is structured as follows: first we describe the altimetry, GRACE, and hydrographic data sets used for the comparison. The criteria for selecting and discarding the suitable profiles and the methodology used to estimate SSL are also outlined. Second, the study of the spatio-temporal distribution of profiles is presented. Third, we show a comparison between SLA and SSL at both seasonal and inter-annual time scales. Final remarks and conclusions are presented in the last section.

\section{DATA}

\section{Altimetry}

Gridded SLA fields were collected from the delayed time (up-to-date) multimission regional product for the Mediterranean Sea produced by AVISO (http://www.aviso.oceanobs.com), which includes merged Topex/Poseidon, ERS 1 and 2, Envisat, and Jason 1 and 2 data. This product provides SLA maps relative to a seven-year (1993-1999) mean. The set of maps (one every seven days from November 1992 to December 2008) is produced on a $1 / 8^{\circ} \times 1 / 8^{\circ}$ Mercator grid (Le Traon et al. 1998, Ducet et al. 2000, SSALTO/DUACS User Handbook). All the standard corrections applied to altimetry data were implemented, including the atmospheric correction. The latter is applied using the Dynamic Atmospheric Correction (DAC) currently delivered by AVISO (Volkov et al. 2007), combining the standard inverted barometer correction and outputs from MOG2D barotropic model (Carrère and Lyard 2003), which improves the representation of high-frequency atmospheric forcing (periods of less than 20 days) as it takes into account both pressure and wind effects. 


\section{GRACE observations}

Monthly values of equivalent water thickness (http://grace.jpl.nasa.gov/data/mass/) based on the Release-04 gravity field from the Center for Space Research (CSR) at the University of Texas, Austin covering the period 2003-2008 were used (Chambers 2006b). Spatial smoothing with a 300-km Gaussian filter was performed on the data. To compensate for the reduction of the signal due to filtering, the time series were multiplied by a factor of 1.3 , which was computed as the ratio of unfiltered and filtered stericcorrected sea level averaged over the basin. A correction for glacial isostatic adjustment (GIA) from the model by Paulson et al. (2007) was also applied to the data after the postglacial rebound Stokes coefficients were converted into estimates of the rate of change of surface mass. The basin-averaged mass contribution to sea level was then obtained.

\section{Hydrographic observations}

The set of in situ T/S profiles used in this study was compiled from the ENACT/ENSEMBLES version 2a (EN3) data set (Ingleby and Huddleston 2007) made available by the Met Office Hadley Centre (http:// www.metoffice.gov.uk/hadobs/en3/). This data set was preferred to the MEDAR product (Rixen et al. 2005), a dedicated gridded hydrographic data set for the Mediterranean Sea with higher spatial resolution, for three reasons: first, not all profiles used to obtain the MEDAR interpolated fields are available, a feature that would handicap the comparison between these products and the original profiles; second, only yearly data are available for the gridded fields, which prevents the analysis from being carried out at intra-annual scales; and third, MEDAR only covers the period up to 2002.

The EN3 data set includes profiles from XBT, CTD and Argo profiling floats from the World Ocean Database'05 (WOD05), the Global Temperature and Salinity Profile Project (GTSPP), Argo and the Arctic Synoptic Basin-Wide Oceanography Project (ASBO). In the current version (v2a) Argo profiles that are suspect of containing errors according to Guinehut et al. (2009) have been rejected. EN3 in situ T/S profiles are available both with and without the XBT and MBT bias corrections applied. In order to explore the impact of these corrections on the estimates of the SSL, we included both data sets in the analysis. The corrections to XBT and MBT depths that have been applied are those by Ishii and Kimoto (2009). In any case, we do not expect the choice of different XBT/MBT bias corrections to have a significant effect on the analysis since most recent estimates of the thermosteric sea level based on different XBT/MBT bias corrections (Levitus et al. 2009, Ishhi and Kimoto 2009, Wijffels et al. 2008) all agree well within the error bars of the estimates.

Quality control flags provided with the data set were used to remove spurious profiles by selecting those with numerical code equal to 1 . However, additional quality checks were necessary as obvious erroneous profiles remained. First, we found profiles with incorrect locations either over land or with bottom depths that were clearly greater than those suggested by the local bathymetry. A total of $53(0.1 \%)$ profiles were excluded following this procedure. Also, some of the profiles $(\sim 0.1 \%)$ were found to have duplicated depths with different values of $\mathrm{T}$ and $\mathrm{S}$. In such cases the value was chosen as the average of the two $T$ and $S$ values, except for those profiles whose values at these levels were significantly different or were different compared with nearby levels; these were rejected. Finally, profiles with no data in the upper $70 \mathrm{~m}$ were also discarded. This resulted in the removal of about $3 \%$ of all profiles. As a result of the quality controls, the total number of 'acceptable' profiles in the Mediterranean Sea is 48168 for the period 1993-2008.

Besides individual profiles, gridded T/S data are also available from the EN3_v2a objective analyses data base (Ingleby and Huddleston 2007). The monthly gridded fields have a spacing of $1^{\circ} \times 1^{\circ}$ and have been obtained using the same profiles used in this work. However, unlike for the in situ profiles, the interpolated data are only available without the XBT or MBT bias corrections applied.

\section{METHODS}

For most profiles, observations do not start at $0 \mathrm{~m}$ but at a deeper depth. As indicated above, profiles that have no data in the upper $70 \mathrm{~m}$ were rejected. However, those profiles for which observations start below $20 \mathrm{~m}$ (but above $70 \mathrm{~m}$ ) may not properly represent the large temporal variability of surface $\mathrm{T} / \mathrm{S}$. In these cases the top metres not covered by observations are substituted by a regionally averaged monthly profile, computed using the monthly interpolated T/S fields (EN3_v2a) within a radius of $500 \mathrm{~km}$ from the in situ profile. Then, the average profile is interpolated onto the vertical levels of the in situ profile with missing data. Finally the missing upper levels of the in situ profile are set to have the same slope as the average profile and the first observation of the in situ profile is set to coincide with the value given by the average profile at the same depth in order to avoid undesirable shifts. For as many as $65 \%$ of the profiles, $\mathrm{S}$ values are missing. In these cases the entire profile is replaced by the regionally averaged $(500 \mathrm{~km})$ monthly $\mathrm{S}$ profile computed from the interpolated fields.

In order to make sure that replacing the missing $S$ profiles by regionally averaged monthly $S$ profiles from the interpolated data did not significantly affect our results, we estimated the uncertainties introduced by this approximation. This is done by first computing two different estimates of the SSL (referenced to $300 \mathrm{~m}$ ) at each profile that has $\mathrm{S}$ data: one using the actual $\mathrm{S}$ profile and one using a monthly profile from the interpolated data. Then, an estimate of the mean er- 
ror in the SSL at individual profiles is computed as the averaged difference between the two estimates of the SSL at each profile. Finally, the error associated with spatially averaged time series of the SSL is computed by propagating the mean error through the averages. The values of the error for the spatial averages of the SSL over the whole Mediterranean, and the western and eastern sub-basins are $0.2 \mathrm{~cm}, 0.4 \mathrm{~cm}$ and $0.3 \mathrm{~cm}$, respectively. These errors correspond to the case in which all $\mathrm{S}$ profiles are replaced by monthly profiles from the interpolated fields. In reality not all profiles are replaced but just $65 \%$ of them; hence we expect the actual errors to be slightly smaller than those provided by our estimate.

Prior to the computation of SSL, all profiles were linearly interpolated onto a set of 42 non-uniform standard vertical levels. For each profile and for each grid point of the interpolated fields, the SSL was then computed relative to the reference depth $H$ as

$$
\operatorname{SSL}(t)=\int_{-H}^{0} \frac{\rho_{0}}{\rho(z, t)} d z-H
$$

where $\rho_{0}$ is a mean density, and $\rho(z, t)$ is the density as a function of time $(t)$ and depth $(z)$.

For the comparison between altimetry and in situ data, SLA weekly maps were interpolated to the time and location of each in situ SSL measurement using a linear space-time interpolation. The performance indicators (i.e. correlation) and regionally averaged time series were calculated on a $1^{\circ} \times 1^{\circ}$ horizontal grid built using observations within a $2^{\circ}$ in longitude and $2^{\circ}$ in latitude box around each grid point for both SLA and in situ SSL. This allows the computation of correlation maps between SLA and SSL estimated from in situ $\mathrm{T} / \mathrm{S}$ profiles. We also performed a standard deviation check in each box, and SSLs larger than three times the box-mean standard deviations were removed.

\section{THE SPATIO-TEMPORAL DISTRIBUTION OF HYDROGRAPHIC PROFILES}

It is proposed that the choice of the reference depth for the computation of SSL be based on the analysis of the spatial and temporal distribution of profiles. Figure 1 depicts the number of yearly profiles with data below $0 \mathrm{~m}$ (all profiles), $300 \mathrm{~m}, 500 \mathrm{~m}, 700 \mathrm{~m}$, and $900 \mathrm{~m}$ and their corresponding percentage of the Mediterranean Sea surface covered. This percentage is estimated as the ratio between the number of $1^{\circ} \times 1^{\circ}$ cells that contain at least one profile and the total number of cells covering the basin. The number of profiles varies significantly from one year to another (Fig. 1A), being larger for the last five years of the period and particularly small for the years 1998, 2001, 2002 and 2003. The number of available profiles is also highly dependent on the vertical coverage: only $68 \%$ of profiles reach $300 \mathrm{~m}$ and only $11 \%$ reach $900 \mathrm{~m}$.
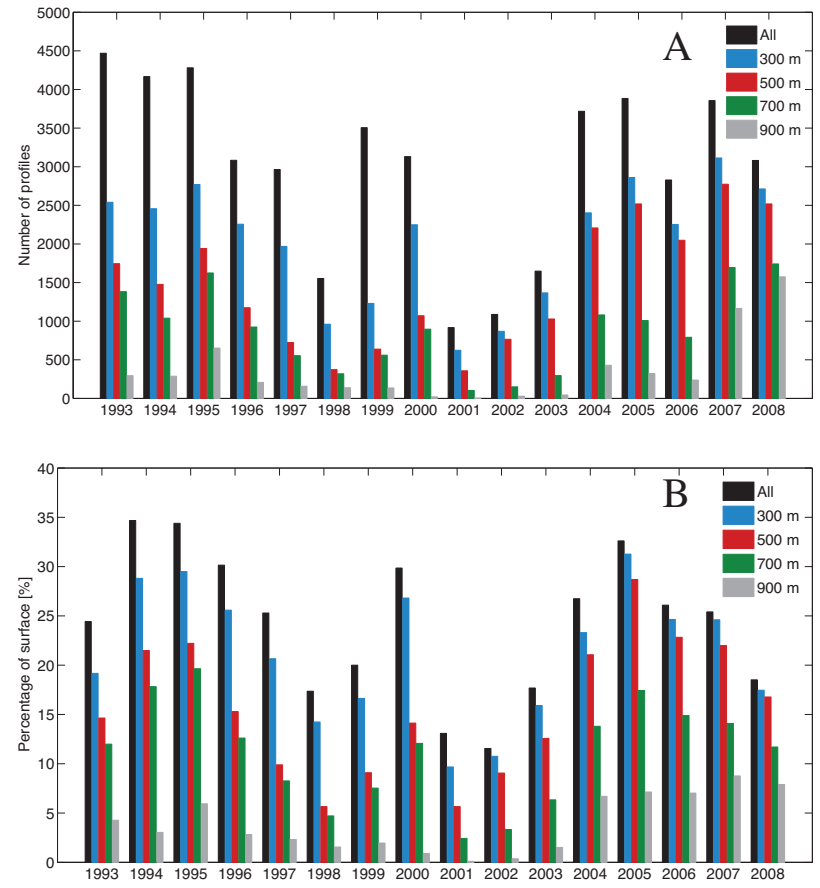

FIG. 1. - A, number of all yearly profiles (black), reaching down to $300 \mathrm{~m}$ (blue), $500 \mathrm{~m}$ (red), $700 \mathrm{~m}$ (green), and $900 \mathrm{~m}$ (grey). B, percentage of the Mediterranean Sea surface covered by the profiles.

The percentage of Mediterranean surface covered by the profiles (Fig 1B) is less than $25 \%$ for all reference depths. It is also worth noting that the area of the basin covered by profiles with data below $300 \mathrm{~m}$ is on average $87 \%$ of that covered by all profiles, reflecting the fact that, despite the reduction in the number of available profiles, the spatial sampling does not significantly deteriorate when the reference depth is chosen at $300 \mathrm{~m}$. This reduction is much greater for deeper levels, ranging from $65 \%$ for a reference depth of $500 \mathrm{~m}$ to only $16 \%$ for a $900 \mathrm{~m}$ reference depth. It is important to note that the discrepancies between reference depths in the number of available profiles and the covered surface are notably smaller for the last 5 years, reflecting the fact that the deployment of Argo floats (after 2004) has significantly increased both the spatial coverage and the depth of the profiles.

Figure 2 shows the spatial distribution of the profiles with $\mathrm{T}$ and $\mathrm{S}$ data for the years of minimum (2001) and maximum (2005) density of observations. The most noteworthy feature is that the number of $\mathrm{T}$ profiles is much larger than that of S profiles, especially in 2001. In fact the spatial coverage of the $S$ profiles is really poor in 2001, although it improves substantially in 2005. The number of T profiles in 2001 is also poor. It is also worth noting that most $\mathrm{T}$ profiles in 2001 are located in very particular areas such as the Alboran Sea, the Algerian Basin or the Gulf of Lions.

The above results suggest that $300 \mathrm{~m}$ should be used as the reference depth to estimate SSL, as the most satisfactory compromise between the number of 
2001
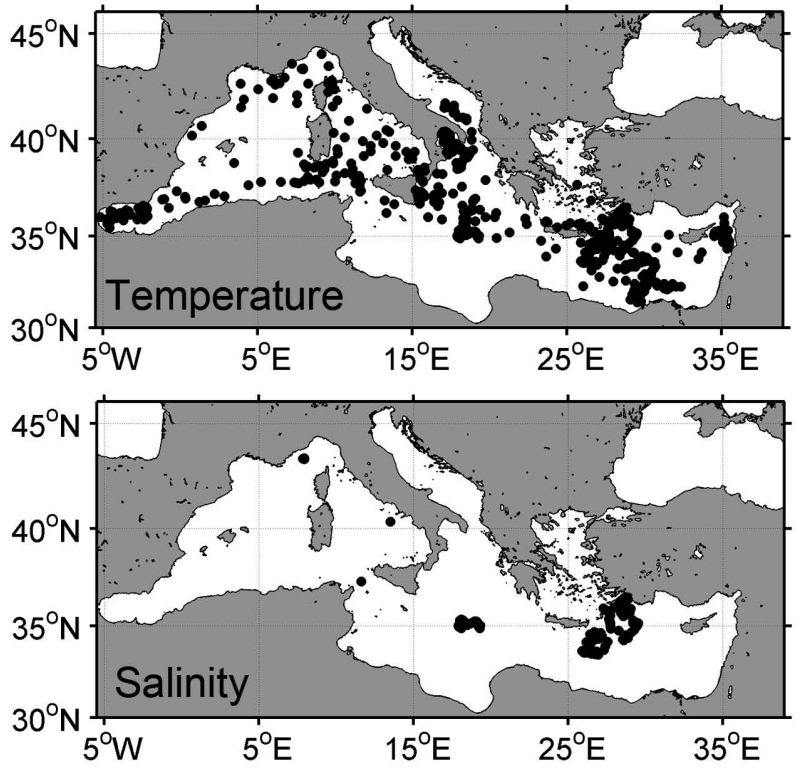
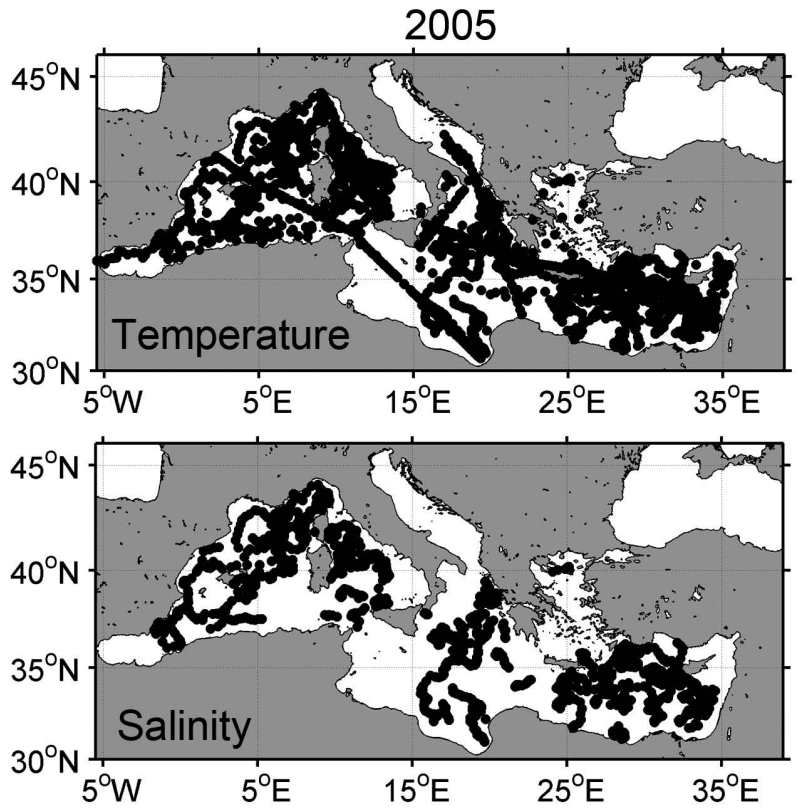

FIG. 2. - Spatial distribution of T (top row) and S (bottom row) profiles with data at or below $300 \mathrm{~m}$ for the years 2001 (left column) and 2005 (right column).

available profiles (and hence between the spatial coverage) and the vertical coverage. It is important to underline that this choice is appropriate for the purpose of studying SSL at a seasonal time scale, but probably not for longer-term studies. Since intermediate and deep layers play an important role at inter-annual and longer time scales, a deeper reference depth would be required for their study.

\section{COMPARISON BETWEEN SLA AND SSL}

\section{Seasonal variability}

SLA observations from altimetry are compared against SSL obtained from both in situ profiles and interpolated data. Correlations between SLA and SSL are mapped in Figure 3. Only significant values at the 95\% confidence level are mapped; otherwise they are blanked. Correlations for the SSL computed using $\mathrm{XBT} / \mathrm{MBT}$ bias-uncorrected profiles are also shown (Fig. 3C). The spatial structure of the correlation is similar for the in situ and interpolated SSL estimates. Both show larger correlations in the eastern than in the western Mediterranean. The lowest correlations are found in the Alboran Sea, the Algerian basin and the Adriatic Sea. Overall, SLA shows larger correlations with SSL computed from in situ data than with SSL computed from interpolated fields. When in situ data are used, correlations are larger than 0.8 and 0.7 in most areas of the eastern and western Mediterranean, respectively. When interpolated data are used, the correlation ranges from 0.5 to 0.8 in most areas of the Mediterranean Sea. In the Adriatic Sea, SSL computed from in situ profiles shows significant correlations (ranging from 0.4 to 0.6 ) only in the southern part of the basin.
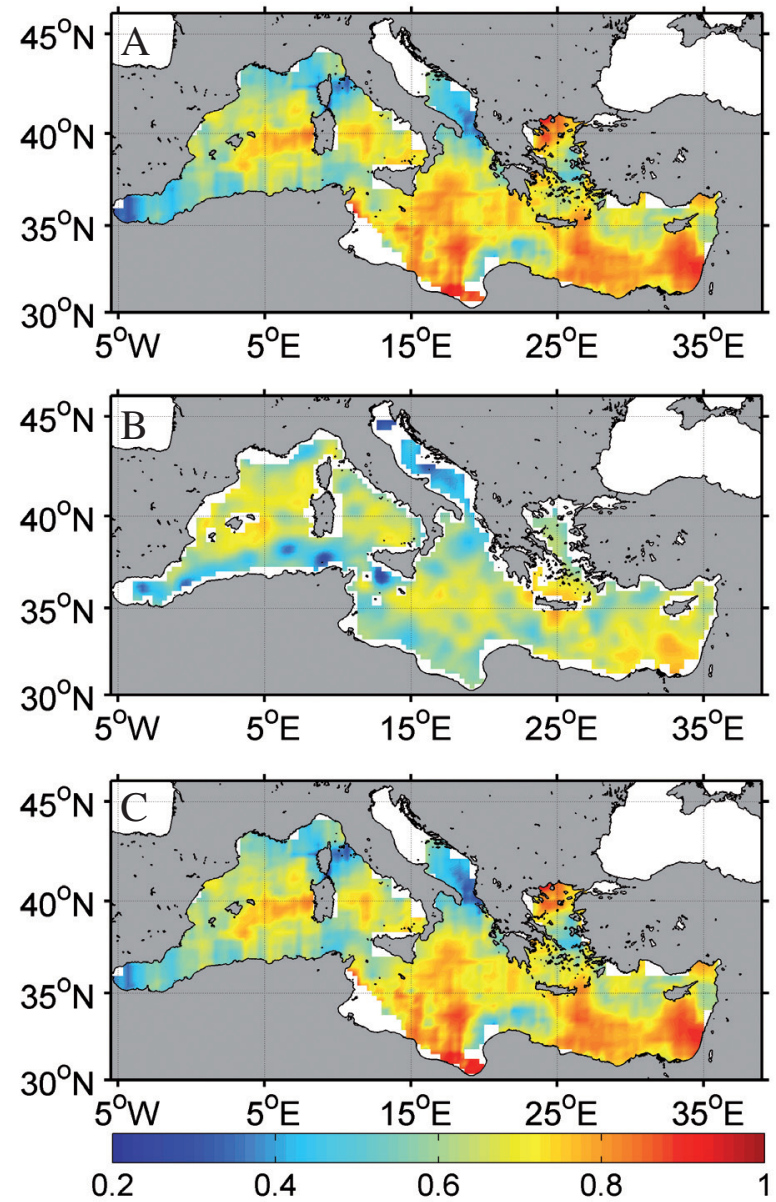

FIG. 3. - Linear correlations between SLA and SSL computed from $\mathrm{XBT} / \mathrm{MBT}$ bias-corrected (A) and uncorrected (C) in situ profiles and interpolated data (B). Integration depth is in both cases $300 \mathrm{~m}$. Points where correlations are non-significant have been masked. 
TABLE 1. - Correlations between spatially averaged SLA from altimetry and SSL computed from in situ profiles (both XBT/MBT bias-corrected and uncorrected) and from interpolated data for the entire Mediterranean Sea (MED) and the western (WMED) and eastern (EMED) Mediterranean sub-basins.

\begin{tabular}{lccc}
\hline & In situ & $\begin{array}{c}\text { In situ } \\
\text { (uncorrected) }\end{array}$ & Interpolated \\
\hline MED & 0.80 & 0.78 & 0.79 \\
WMED & 0.59 & 0.58 & 0.74 \\
EMED & 0.79 & 0.77 & 0.78 \\
\hline
\end{tabular}

SSL computed from interpolated fields is significantly correlated with SLA in larger areas, but correlation values are lower than 0.5 everywhere. It is also worth noting that differences between correlation maps for the SSL from bias-corrected and uncorrected profiles are nearly indistinguishable. Hence it is derived that differences between in situ and interpolated SSL in some regions are probably due to the mapping method and the lack of profiles. The use of a large interpolation radius introduces information from distant profiles that, in regions of intense mesoscale activity, is often not representative of the regional variability.

The temporal variability of SLA and SSL was also examined. For this comparison the SSL was also computed using XBT/MBT bias-uncorrected profiles.
Monthly time series of SLA and SSL estimated from both in situ and interpolated data are plotted in Figure 4 (time series of the SSL from the uncorrected profiles are not shown as they are very similar to those from the corrected data, so they add no new information) for the entire Mediterranean Sea, the western basin and the eastern basin (the Adriatic Sea is excluded in the latter). The correlation between these curves is listed in Table 1. Correlations between SLA and SSL from uncorrected T/S profiles are also shown. Note that these values correspond to correlations between spatially averaged time series. This is why the SSL computed from interpolated data display correlations considerably larger than those mapped in Figure 3B, which correspond to single point time series. Therefore, though SSL computed from profiles performs better than SSL computed from interpolated fields at individual points and small regions, for spatially averaged values and at basin and sub-basin scale their performance is similar. It is also interesting to note that there are no significant differences between the SSL from the XBT/MBT biascorrected and uncorrected profiles in terms of their correlation with SLA at seasonal scales.

Figure 4 also shows that SLA and SSL are highly correlated mostly due to the dominant role of the seasonal cycle. The basin-averaged time series are all very
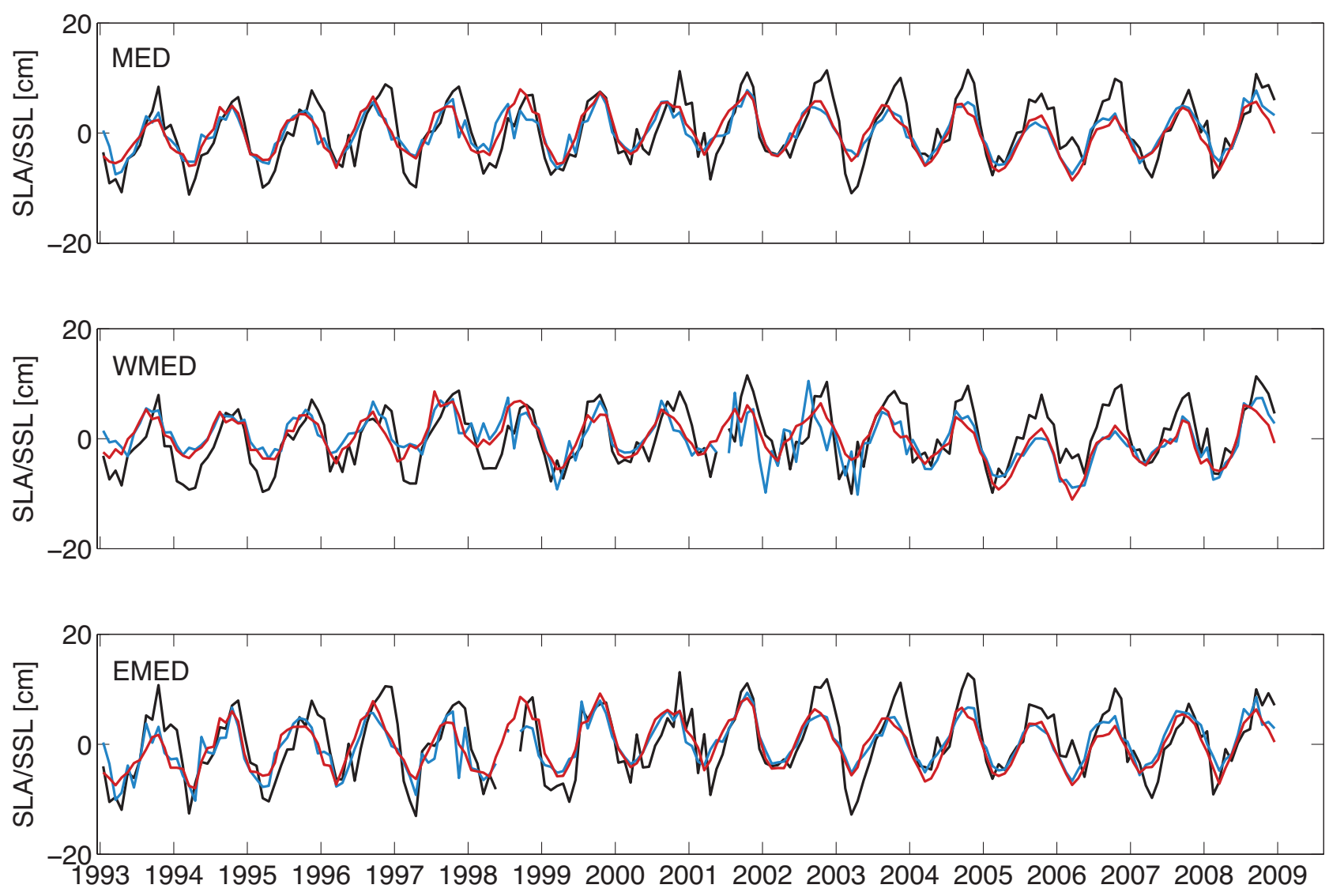

FIG. 4. - Monthly time series of SLA (black) interpolated to the profile locations and SSL computed from XBT/MBT bias-corrected in situ profiles (blue) and from interpolated data (red) averaged over the entire Mediterranean basin (MED), and the western (WMED) and eastern (EMED) Mediterranean sub-basins. 
TABLE 2. - Annual amplitude and phase of spatially averaged time series of the SLA from altimetry and the SSL from in situ profiles (both XBT/MBT bias-corrected and uncorrected) and interpolated data computed over the entire Mediterranean Sea (MED) and the western (WMED) and eastern (EMED) Mediterranean sub-basins.

\begin{tabular}{lcccc}
\hline $\begin{array}{l}\text { Amplitude/Phase } \\
\text { [cm]/[days] }\end{array}$ & Altimetry & In situ & $\begin{array}{c}\text { In situ } \\
\text { (uncorrected) }\end{array}$ & Interpolated \\
\hline MED & $6.8 \pm 0.3 / 268 \pm 2$ & $4.5 \pm 0.2 / 249 \pm 2$ & $4.4 \pm 0.2 / 248 \pm 2$ & $5.0 \pm 0.1 / 246 \pm 2$ \\
WMED & $6.2 \pm 0.3 / 262 \pm 3$ & $4.1 \pm 0.3 / 247 \pm 4$ & $4.1 \pm 0.3 / 247 \pm 4$ & $4.3 \pm 0.2 / 243 \pm 3$ \\
EMED & $7.3 \pm 0.3 / 271 \pm 2$ & $5.0 \pm 0.2 / 251 \pm 3$ & $4.9 \pm 0.2 / 248 \pm 2$ & $5.4 \pm 0.2 / 249 \pm 2$ \\
\hline
\end{tabular}

similar, reflecting correlation values as high as 0.8 . The main difference is that for the basin-averaged series the annual amplitude of the SLA cycle is greater than that of the SSL cycle. It is also worth noting that SSL computed from interpolated fields results in smoother averaged time series than SSL computed from profiles. In the western Mediterranean the latter performs worse than the interpolated SSL in terms of correlation. This can be explained by the lack of data for the years 1998 , 2001, 2002 and 2003 (Fig. 1), when the number of profiles in the western Mediterranean is very scarce. The greatest differences between interpolated and in situ SSL are actually found during those years (Fig. 4). When they are removed from the time series, the correlation between SLA and in situ SSL increases to 0.72 , a figure comparable with that for the SSL from interpolated data. This lack of data for particular years has a weaker effect on the interpolated SSL because of the use of a large radius of interpolation, which allows the inclusion of more profiles when the gridded $\mathrm{T}$ and $\mathrm{S}$ fields are derived. Because the seasonal cycle is the dominant signal and it has a similar phase in most regions of the basin (Marcos and Tsimplis 2007), the inclusion of distant profiles improves the correlation. In the eastern Mediterranean all time series are in very good agreement, showing correlations of nearly 0.8 . This is the clearest example of how spatially averaged SSL and SLA compare better than single points, especially for the interpolated SSL: when the grid point correlations mapped in Figure 3 are averaged for that region, correlations are 0.72 for in situ SSL and 0.63 for interpolated SSL.

Annual amplitudes and phases for the entire Mediterranean Sea and the eastern and western basins are summarized in Table 2. It is worth noting that the differences between XBT/MBT bias-corrected and uncorrected in situ SSL are also non-significant when the annual amplitudes and phases are considered. The annual cycle of the SLA shows greater amplitude (between 6 and $7 \mathrm{~cm}$ ) and peaks about two weeks later than that of the SSL (with an amplitude between 4 and $5 \mathrm{~cm}$ ) in all basins. The annual amplitude in the eastern basin is about $1 \mathrm{~cm}$ greater than that in the western basin for both SLA and SSL. The values of the amplitudes and phases given by the in situ and interpolated SSL are in good agreement in all basins, although annual amplitudes are slightly larger in the latter.

It is important to note that for the comparison between SLA and SSL at seasonal scales we have assumed that the mass component of sea level is sig-
TABLE 3. - Correlations between spatially averaged SLA from altimetry before and after the removal of the mass component from GRACE and the SSL from in situ profiles (both corrected and uncorrected) and interpolated data over the whole Mediterranean basin for the period 2003-2008

\begin{tabular}{lcc}
\hline Correlation & SLA & SLA-GRACE \\
\hline SSL in situ & 0.82 & 0.91 \\
In situ (uncorrected) & 0.81 & 0.90 \\
Interpolated & 0.80 & 0.91 \\
\hline
\end{tabular}

nificantly smaller than the steric component. The validity of this assumption is confirmed by a series of recent studies that have used GRACE observations to study the mass component in the Mediterranean Sea (Fenoglio-Marc et al. 2006, Calafat et al. 2010, GarcíaGarcía et al. 2010). In order to explore the impact of such assumption in our analysis, we have used GRACE observations for the period 2003-2008 to estimate and remove the mass component from the SLA. Because of the low horizontal spatial resolution of the GRACE observations ( $1000 \mathrm{~km}$, Chambers 2006a), it is not possible to compute spatial maps of the mass component in the Mediterranean. Hence, in this case we focus on averages over the whole Mediterranean basin. Correlations between SLA before and after the removal of the mass component and the SSL from in situ profiles (both corrected and uncorrected) and the interpolated data are summarized in Table 3. Correlations increase from about 0.80 to about 0.90 when the mass component is removed from the SLA, reflecting the fact that the mass component plays only a small role when the seasonal cycle of the total sea level is considered.

We also computed the annual amplitudes and phases of all time series for the period 2003-2008 (Table 4). The first thing we note is that the difference of two weeks found between the phase of the annual cycle from SLA and that from the SSL is due to the mass component, which is included in the former. After the

TABLE 4. - Annual amplitudes and phases of spatially averaged SLA from altimetry before and after the removal of the mass component from GRACE and the SSL from in situ profiles (both corrected and uncorrected) and interpolated data over the whole Mediterranean basin for the period 2003-2008.

\begin{tabular}{lcc}
\hline & Amplitude (cm) & Phase (days) \\
\hline SLA & $6.8 \pm 0.3$ & $262 \pm 2$ \\
SLA-GRACE & $7.2 \pm 0.4$ & $247 \pm 3$ \\
SSL in situ & $4.9 \pm 0.2$ & $248 \pm 2$ \\
SSL in situ (uncorrected) & $4.7 \pm 0.2$ & $248 \pm 2$ \\
SSL interpolated & $4.9 \pm 0.2$ & $245 \pm 2$ \\
\hline
\end{tabular}


removal of the mass component we find perfect agreement in phase among all estimates of the SSL, including the SSL estimate from SLA. Also noteworthy is the fact that the annual amplitudes of the SSL from both in situ profiles and interpolated data are considerably smaller than those from the mass-corrected SLA. The underestimation of the annual amplitudes of the SSL by the EN3 data set has already been reported in previous studies (e.g. García-García et al. 2010).

\section{Inter-annual variability}

So far we have focused our attention on the comparison between SLA and SSL at seasonal scales. To carry the comparison a step further to longer time scales (i.e. inter-annual time scales) is not easy because: (i) the mass component becomes the dominant component of sea level, and thus has to be properly removed from the SLA before the comparison with the SSL; and (ii) intermediate and deep layers play a more important role in the SSL at these time scales, and hence a deeper reference depth is required for the computation of the SSL from hydrographic observations. Difficulty (i) can be overcome by using GRACE observations to estimate the mass component and remove it from the SLA, although this is only possible from 2003 and should only be applied to spatial averages over the whole Mediterranean basin. Difficulty (ii) has no simple solution since we have shown that the number of in situ T/S profiles decreases nearly exponentially with increasing depth. The approach taken here consists of extending the reference depth used to compute the SSL deeper to $500 \mathrm{~m}$. This seems to be a reasonable approach for the period 2004-2008 as the number of profiles and the surface covered has not decreased substantially at this depth for this period (see Fig. 1).

De-seasoned monthly time series of the masscorrected SLA and the SSL from in situ profiles and interpolated data spatially averaged over the whole Mediterranean basin are shown in Figure 5. The first thing we note is that the variability shown by the mass-corrected SLA is greater than that shown by the SSL computed from hydrographic observations. The standard deviation of the time series is $2.0 \mathrm{~cm}$ for the mass-corrected SLA, $1.5 \mathrm{~cm}$ for the SSL from in situ profiles and $1.3 \mathrm{~cm}$ for the SSL from interpolated data. Hence the underestimation is greater when interpolated data are used. The inter-annual variability of the masscorrected SLA is not in very good agreement with any of the other SSL estimates. However, it is worth noting that the general negative trend between 2003 and 2005 and the positive trend between 2006 and 2008 shown by the mass-corrected SLA is well captured by the SSL from both in situ profiles and interpolated data. In order to quantify the agreement between the mass-corrected SLA and the SSL from T/S observations, we computed the correlations between the time series. Correlations are low (below 0.40) in all cases, although they are significant at the $95 \%$ confidence level. The highest

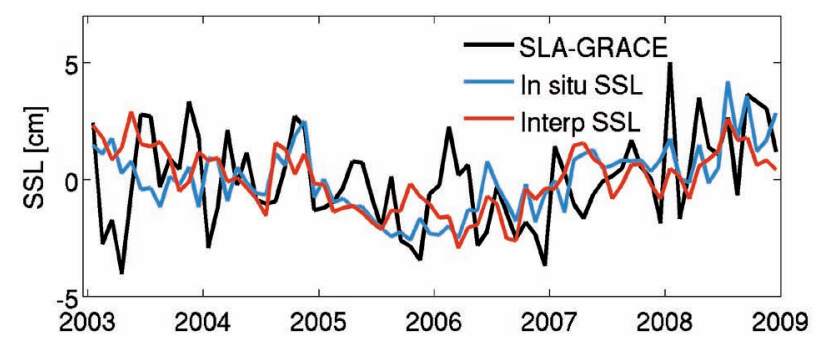

Fig. 5. - De-seasoned monthly time series of SLA minus the mass component from GRACE (black) and SSL computed from XBT/ MBT bias-corrected in situ profiles (blue) and from interpolated data (red) spatially averaged over the entire Mediterranean basin.

correlation (0.39) is obtained when using XBT/MBT bias-corrected in situ profiles while the lowest correlation is found when using interpolated data $(0.29)$. The correlation when using uncorrected in situ profiles is 0.35 . Hence, the difference between the SSL from bias-corrected and uncorrected in situ profiles is small also at inter-annual scales, although it is larger than at seasonal scales. The correlation between the SSL from in situ profiles and that from the interpolated data is 0.70 . It is also worth mentioning that no significant correlations are found when SLA is compared directly with SSL, without removing the mass component.

\section{DISCUSSION AND CONCLUSIONS}

At seasonal time scales the dominant signal in the Mediterranean sea level is the seasonal cycle caused by the seasonal expansion and contraction of the ocean water volume (Fenoglio-Marc 2002, Criado-Aldeanueva et al. 2008, Tsimplis et al. 2009). While SSL accounts for such effects of density changes in sea level, SLA measurements also include mass variations due to changes in the terrestrial storage of freshwater and/ or to water mass redistributions (the barotropic component). The mass component has been shown to be significantly smaller than the steric component in the Mediterranean Sea at seasonal time scales (FenoglioMarc et al. 2006, Calafat et al. 2010, García-García et al. 2010), so a direct comparison between SLA and SSL is reasonable. At longer time scales the mass component becomes the major source of temporal variability, and thus needs to be removed from the SLA before its comparison with the SSL.

When correlations between SLA and the steric component are computed, results depend on the ability of SSL to mimic the seasonality of total sea level. Gridded data make use of T/S profiles located at great distances from each other because of the large interpolation radius (a few hundred $\mathrm{km}$ ). Because the amplitude and phase of the seasonal cycle change smoothly, these can still be representative of the seasonal cycle at a given point. The exception would be when profiles located in clearly differentiated areas are merged. This is the case of the Adriatic, where the use of interpolated data is not advisable because it involves bringing 
in observations from outside the region that are clearly not representative of the T/S local variability. Results are not much better for SSL computed from profiles, although in this case the reason is the lack of in situ observations. Another, even more critical case is the Black Sea (not shown in this study), where there is no profile in the data base, but interpolated data are computed in the EN3 data base, likely using nearby Mediterranean profiles.

The spatial and temporal distribution of the in situ Mediterranean profiles reveals that both the number of profiles and the surface covered vary significantly from one year to another and for different depths. The surface covered by the profiles is less than $35 \%$ of the total Mediterranean basin for every year in the period 1992-2008. Notably, both the area covered and the maximum sampled depth increase significantly with the deployment of the Argo floats: during the last 5 years of the period analysed most profiles reached depths greater than 500 $\mathrm{m}$ and a large number of them reached $900 \mathrm{~m}$ during the last two years (2007 and 2008). This supports the extended evidence of the importance of the Argo floats in ocean monitoring also for semi-enclosed and relatively small seas such as the Mediterranean Sea. For the period prior to 2004, a considerable number of profiles have no data below $300 \mathrm{~m}$.

At seasonal time scales, the SSL was computed using $300 \mathrm{~m}$ as the reference depth for integration of density anomalies and it was compared with SLA from altimetry. Correlations between SLA and SSL computed from profiles are greater than those for interpolated SSL almost everywhere in the Mediterranean Sea. The differences between the two SSL estimates are reduced when spatially averaged time series are computed over selected regions. It has also been found that the correlation between SLA and SSL is smaller in the western basin than in the eastern basin for both SSL estimates. This is partly explained by the uneven spatial distribution of the profiles, which in the western basin are concentrated in areas of intense mesocale activity (i.e. the Alboran Sea and the Algerian basin) or deep convection (i.e. the Gulf of Lions), simply because oceanographic surveys are carried out in areas that are more interesting from the oceanographic point of view (see Fig. 2). The mesoscale activity in the Alboran and Algerian basins is mainly driven by the inflow of Atlantic water through the Gibraltar Strait, which results in the formation of large anticyclonic eddies (Herburn and La Violette 1990, Vargas-Yáñez et al. 2002). In the Algerian basin some of these eddies extend almost down to the bottom and have a large barotropic component that is not captured when SSL is computed. Deep convection in the Gulf of Lions activates a cyclonic circulation that generates appreciable vertical mixing with the surrounding deep water masses (Herrmann et al. 2008, Schroeder et al. 2008), so intermediate and deep layers make a significant contribution to sea level variability. SSL computed relative to $300 \mathrm{~m}$ probably misses a larger part of the sea level variability in these areas, resulting in a lower correlation with SLA from altimetry.

In general, in regions and during periods for which either the contribution of intermediate and deep layers (below $300 \mathrm{~m}$ ) to SSL or the barotropic component of the SLA are of the same order as the SSL referenced to $300 \mathrm{~m}$, the comparison between SSL and SLA must be taken with caution. An example of such a discrepancy is found in the western Mediterranean during the years 2005 and 2006 (Fig. 4), which were characterized by a major renewal of the deep waters of the western Mediterranean (Schroeder et al. 2008), with a clear signature on total sea level (Herrmann et al. 2009). The fact that the seasonal cycle of SSL computed for the upper $300 \mathrm{~m}$ is clearly smaller than the SLA cycle suggests that deeper layers played an important role during that period. In order to explore the role played by the mass component in the differences between the SLA and SSL cycle, we removed an estimate of the mass component from GRACE observations from the SLA. This is only possible for the period 2003-2008 and only for spatial averages over the whole basin. At seasonal scales, correlations between the spatially averaged mass-corrected SLA and SSL increase in general from 0.8 to 0.9 . Also, after the removal of the mass component, the annual phase of the basin-averaged mass-corrected SLA is in perfect agreement with that of the SSL. However, the annual amplitudes from the SSL are still much smaller than those from the mass-corrected SLA, confirming the large contribution of the deeper layers. The study of temporal variability also showed that the difference between using XBT/MBT bias-corrected and uncorrected in situ profiles is not significant at seasonal scales. Hence differences between in situ and interpolated SSL are more related to the mapping method than to the fact that the XBT/MBT bias was corrected in the former but not in the latter.

The temporal variability of the basin-averaged SSL was also explored at inter-annual scales for the period 2003-2008. In this case the reference depth was chosen at $500 \mathrm{~m}$. At inter-annual scales it is essential to remove the mass component from the SLA data before comparing them with the SSL, as this component becomes dominant. The mass component was estimated using GRACE observations. The results show that neither the SSL from in situ profiles nor that from interpolated data explains much of the mass-corrected SLA variability. Correlations are lower than 0.4 in all cases, reflecting the considerable contribution of the intermediate and deep layers. The higher correlation is found when XBT/MBT bias-corrected in situ profiles (0.39) are used, suggesting that at longer than seasonal time scales the Mediterranean mean SSL is better estimated using in situ profiles than interpolated data. It is also worth mentioning that at these time scales the difference between SSL estimated from bias-corrected and uncorrected in situ profiles is greater than at seasonal scales, although still small (a correlation of 0.35 with mass-corrected SLA as compared to 0.39 for corrected in situ profiles). 
Summarizing, the main conclusions of this study are:

(i) When computing SSL from interpolated $\mathrm{T}$ and $\mathrm{S}$ fields relative to a depth greater than $300 \mathrm{~m}$ in the Mediterranean Sea, one should be aware of the fact that very little new information is added. Moreover, if new information exists, it could come from observations taken very far away from the study area and could thus lead to wrong results and conclusions if the areas have clearly differentiated thermohaline characteristics. This limitation applies mainly to coarse-resolution global data bases and less to higher-resolution products such as MEDAR. However, the use of MEDAR in this context is limited by other factors (see data description section). For the last two years of the period analysed (2007 and 2008) the reference depth could be chosen at 700 or even at $900 \mathrm{~m}$, as both the number of profiles with data below those depths and the spatial coverage increases significantly during those years. Conversely, for most of the period the number of profiles and the spatial coverage of hydrographic observations are very limited, reducing the representativeness of SSL in areas where intermediate and deep water formation processes occur.

(ii) SSL computed using interpolated T/S fields is comparable to SSL from in situ profiles for spatially averaged time series at basin and sub-basin scales, when the top $300 \mathrm{~m}$ are chosen as the reference depth for integration. This is in spite of the bias corrections applied to the profiles and not to the interpolated fields. Results using SSL from in situ profiles without XBT/ MBT corrections show no significant differences when compared with the SSL from corrected data at seasonal scales. Moreover, all estimates of the SSL are highly correlated with SLA from altimetry at intra-annual time scales. When small areas or individual grid points are to be used, it is advisable to compute SSL using nearby profiles instead, whenever these are available.

iii) Estimates of the SSL from both in situ profiles and interpolated data significantly underestimate the annual amplitude of the SLA. This is so even after the removal of the mass component using GRACE observations, which suggests that the role played by the intermediate and deep layers is important. The importance of these layers becomes even more evident at inter-annual time scales. Correlations between the basin-averaged mass-corrected SLA and SSL are significantly lower at inter-annual time scales than at seasonal scale. Also, the SSL at inter-annual time scales seems to be better estimated using in situ profiles than interpolated data.

A question remains open about the actual accuracy of the estimated SSL at inter-annual time scales. The scarcity of data at deeper layers, especially for the earlier period, the uneven horizontal distribution of profiles and the heterogeneous observational instrumentation are factors to be considered as sources of uncertainty in the estimation of SSL. More research is needed in this respect, and will probably be facilitated when a longer period of Argo data is made available.

\section{ACKNOWLEDGEMENTS}

This study has been carried out in the framework of the projects VANIMEDAT-2 (CTM200910163-C02-01, funded by the Spanish Marine Science and Technology Program and the E-Plan of the Spanish Government) and ESCENARIOS (funded by the Agencia Estatal de Meteorología). F.M. Calafat acknowledges a research contract funded by that project and M. Marcos acknowledges a "Ramón y Cajal" contract funded by the Spanish Ministry of Education. Altimetry data were provided by AVISO (http://www. aviso.oceanobs.com/). GRACE data were processed by D.P. Chambers, supported by the NASA MEASURES Programme, and are available at http://grace.jpl.nasa. gov. The authors are grateful to Prof. Damià Gomis for his advice and comments on the manuscript.

\section{REFERENCES}

Antonov J.I., Levitus S., Boyer T.P. 2005. Thermosteric sea level rise, 1955-2003. Geophys. Res. Lett. 32: L12602.

Calafat F.M., Marcos M., Gomis D. 2010. Mass contribution to the Mediterranean Sea level variability for the period 1948-2000. Global Planet. Change 73: 193-201.

Carrère L., Lyard F. 2003. Modeling the barotropic response of the global ocean to atmospheric wind and pressure forcing - comparisons with observations. Geophys. Res. Lett. 30(6): 1275.

Cazenave A., Dominh K., Guinehut S., Berthier E., Llovel W., Ramillien G., Ablain M., Larnicol G. 2009. Sea level budget over 2003-2008: A reevaluation from GRACE space gravimetry, satellite altimetry and Argo. Global Planet. Change 65: 83-88.

Cazenave A., Llovel W. 2010. Contemporary sea level rise. Annu. Rev. Mar. Sci. 2: 145-73.

Chambers D.P. 2006a. Observing seasonal SSL variations with GRACE and satellite altimetry. J. Geophys. Res. 111: C03010.

Chambers D.P. 2006b. Evaluation of New GRACE Time-Variable Gravity Data over the Ocean. Geophys. Res. Lett. 33(17): L17603.

Criado-Aldeanueva F., Del Río Vera J., García-Lafuente J. 2008. Steric and mass induced Mediterranean sea level trends from 14 years of altimetry data. Global Planet. Change 60: 563-575.

Dhomps A.L., Guinehut S., Le Traon P.Y., Larnicol G. 2011. A global comparison of Argo and satellite altimetry observations. Ocean Sci. 7: 175-183.

Domingues C.M., Church J.A., White N.J., Glecker P.J., Wijffels S.E., Barker P.M., Dunn J.R. 2008. Improved estimates of upper-ocean warming and multi-decadal sea level rise. Nature 453: 1090-1094.

Ducet N., Le Traon P.Y., Reverdin G. 2000. Global high-resolution mapping of ocean circulation from the combination of T/P and ERS-1/2. J. Geophys. Res. 105: 19477-19498.

Fenoglio-Marc L., 2002. Long-term sea level change in the Mediterranean Sea from multi-satellite altimetry and tide gauges. Phys. Chem. Earth 27: 1419-1431.

Fenoglio-Marc L., Kusche J., Becker M. 2006. Mass variation in the Mediterranean Sea from GRACE and its validation by altimetry, steric and hydrologic fields. Geophys. Res. Lett. 33: L19606.

García-García D., Chao B.F., Boy J.-P. 2010. Steric and massinduced sea level variations in the Mediterranean Sea revisited. J. Geophys. Res. 115: C12016.

Gouretski V., Koltermann K.P. 2007. How much is the ocean really warming? Geophys. Res. Lett. 34: L01610.

Guinehut S., Le Traon P.Y., Larnicol G. 2006. What can we learn from Global Altimetry/Hydrography comparisons? Geophys. Res. Lett. 33: L10604.

Guinehut S., Coatanoan C., Dhomps A.L., Le Traon P.Y., Larnicol G. 2009. On the use of satellite altimeter data in Argo quality control. J. Atmos. Oceanic Technol. 26: 395-402. 
Herburn G.W., La Violette P. 1990. Variations in the structure of the anticyclonic gyres found in the Alboran Sea. J. Geophys. Res. 95 (C2): 1599-1613.

Herrmann M., Somot S., Sevault F., Estournel C., Déqué M. 2008. Modeling the deep convection in the northwestern Mediterranean Sea using an eddy-permitting and eddy-resolving model: Case study of winter 1986-1987. J. Geophys. Res. 113: C04011.

Herrmann M., Bouffard J., Beranger K. 2009. Monitoring openocean deep convection from space. Geophys. Res. Lett. 36: L03606.

Ingleby B., Huddleston M. 2007. Quality control of ocean temperature and salinity profiles - historical and real-time data. J. Mar Syst. 65: 158-175.

Ishii M., Kimoto M. 2009. Reevaluation of historical ocean heat content variations with time-varying XBT and MBT depth bias corrections. J. Oceanogr. 65: 287-299.

Le Traon P.-Y., Nadal F., Ducet N. 1998. An improved mapping method of multisatellite altimeter data. J. Atmos. Oceanic Technol. 15: 522-534

Levitus S., Antonov J.I., Boyer T.P., Locarnini R.A., Garcia H.E., Mishonov A.V. 2009. Global ocean heat content 1955-2008 in light of recently revealed instrumentation problems. Geophys. Res. Lett. 36: L07608.

Lombard A., Cazenave A., Le Traon P.Y., Ishii M. 2005. Contribution of thermal expansion to present-day sea-level change revisited. Global Planet. Change 47: 1-16.

Lyman J.M., Good S.A., Gouretski V.V., Ishii M., Johnson G.C., Palmer M.D., Smith D.M., Willis J.K. 2010. Robust warming of the global upper ocean. Nature 465: 334-337.

Marcos M., Tsimplis M.N. 2007. Variations of the seasonal sea level cycle in southern Europe. J. Geophys. Res. 112: C12011.

Marcos M., Calafat F.M., Llovel W., Gomis D., Meyssignac B. 2011. Regional distribution of steric and mass contributions to sea level changes. Global Planet. Change 76: 206-218.

Paulson A., Zhong S., Wahr J. 2007. Inference of mantle viscosity from GRACE and relative sea level data. Geophys. J. Int. 171: 497-508
Rixen M.,Beckers J.M., Levitus S., Antonov J.I., Boyer T, Maillard C., Fichaut M., Balopoulos E., Iona S., Dooley H., Garcia M.J., Manca B., Giorgetti A., Manzella G., Mikhailov N., Pinardi N., Zavatarelli M., the Medar Consortium 2005. The Western Mediterranean Deep Water: a proxy for climate change. Geophys. Res. Lett. 32: L12608.

Schroeder K., Ribotti A., Borghini M., Sorgente R., Perilli A., Gasparini G.P. 2008. An extensive western Mediterranean deep water renewal between 2004 and 2006. Geophys. Res. Lett. 35: L18605.

Ssalto/Duacs User Handbook: (M)SLA and (M)ADT Near-Real Time and Delayed Time Products. SALP-MU-P-EA-21065-CLS.

Tsimplis M.N., Marcos M., Colin J., Somot S., Pascual A., Shaw A.G.P. 2009. Sea level variability in the Mediterranean Sea during the 1990s on the basis of two $2 \mathrm{~d}$ and one $3 \mathrm{~d}$ model. J. Mar. Syst. 78: 109-123.

Vargas-Yáñez M., Plaza F., García-Lafuente J., Sarhan T., Vargas J.M., Velez-Belchi P. 2002. About the seasonal variability of the Alboran Sea circulation. J. Mar. Syst. 35: 229-248.

Volkov D.L., Larnicol G., Dorandeu J. 2007. Improving the quality of satellite altimetry data over continental shelves. J. Geophys. Res. 112: C06020.

Wijffels S., Willis J.K., Domingues C.M., Barker P., White N.J., Gronell A., Ridgway K., Church J.A. 2008. Changing expendable bathythermograph fall rates and their impact on estimates of thermosteric sea level rise. J. Climate 21: 5657-5672.

Willis J.K., Lyman J.M., Johnson G.C., Gilson J. 2009. In situ data biases and recent ocean heat content Variability. J. Atmos. Oceanic Technol. 26: 846-852.

Willis J.K., Chambers D.P., Kuo C.Y., Shum C.K. 2010. Global sea level rise: Recent progress and challenges for the decade to come. Oceanography 23(4): 26-35.

Scient. ed.: J. Font.

Received September 26, 2011. Accepted March 22, 2012.

Published online August 2, 2012. 